E.L.U.A., 6, 1990, pp: 47-72.

\title{
PARA UNA CARACTERIZACIÓN TIPOLÓGICA DE LOS TEXTOS CONSTITUCIONALES (A PROPÓSITO DE LOS TEXTOS CONSTITUCIONALES IBEROAMERICANOS) ${ }^{1}$
}

\author{
AGUSTÍN VERA LUJÁN \\ (Universidad de Murcia)
}

El sentido y la rentabilidad explicativa de la categoría texto resultan directamente de una teoría lingüística articulada sobre el concepto de nivel.

Esta categoría explicativa se cuenta sin duda entre los recursos metodológicos de mayor importancia para la conformación válida de cualquier modelo lingüístico deductivo. En la lingüística actual se maneja con dos sentidos distintos, aunque próximos, según se considere su formulación en modelos formalizados o no. En el segundo caso - el de los modelos denominados «estructuralistas»nivel es sinónimo de cada etapa del análisis en que es posible/necesario estudiar problemas de naturaleza semejante ${ }^{2}$. En el primero, el de los modelos «generativos», nivel $\longrightarrow$ componente-, en consonancia con el carácter formalizado de estos modelos, denota el conjunto de unidades y reglas que comparten las mismas restricciones generales de funcionamiento ${ }^{3}$.

Salvadas estas diferencias, la utilización que del concepto de nivel se hace en las distintas metodologías linguísticas tiene que ver con la necesidad de reducir la complejidad «real» del objeto estudiado mediante el recurso a su no consideración global como tal ente real; procediendo, al contrario, en virtud de aproximaciones parciales en cada una de las cuales se tomará en consideración el mismo tipo de fenómenos generales. Sólo, por consiguiente, tras el estudio de la totalidad de los niveles lingüísticos que pueden/deben ser establecidos

'Este trabajo ha sido realizado en el marco del Proyecto de Investigación PB87-0839 de la D.G.I.C.Y.T. del Ministerio de Educación y Ciencia.

${ }^{2}$ Cfr., a título de ejemplo, G. Rojo: Aspectos básicos de sintaxis funcional, Málaga, Agora, 1983, pp: 28.

${ }^{3}$ Aspectos de la teoría de la sintaxis, Madrid, Aguilar, 1975, pp: 206. 
será posible considerar cumplida la explicación del funcionamiento de una lengua en su integridad.

La explicación del funcionamiento de un sistema lingüístico como resultado de la operatividad de distintos niveles es, pues, un recurso metodológico para acceder a la explicación o comprensión de dicho sistema; una convención que permite considerar en cada momento aspectos parciales de un sistema cuya operatividad es objetivamente global.

La historia misma de la investigación lingüística puede ser caracterizada como una progresiva ampliación en el número y la complejidad de los niveles tomados en consideración, hasta la formulación del nivel más recientemente establecido: el textual.

La unidad denominada texto es característica del nivel lingüístico correspondiente, el nivel textual, cuya formulación es consecuencia de la existencia de propiedades lingüísticas específicas de dicho nivel y definitorias, por tanto, de la unidad que le es propia. Tales propiedades tienen que ver con la dimensión comunicativa de lo textual; con la posibilidad/necesidad de consideración de las lenguas históricas como instrumentos comunicativos. En este sentido, desde una perspectiva funcionalista (caracterizadora de los niveles y unidades lingüísticos en virtud de la función que les es privativa), el texto puede ser definido como la menor unidad dotada de autonomía comunicativa ${ }^{4}$.

El texto es una unidad de comunicación, y el nivel textual, en consecuencia, un nivel donde los factores que han de ser tomados en consideración son factores de naturaleza comunicativa. Dado que ninguna relación comunicativa es imaginable al margen de la vinculación que, a través de determinados mensajes, establecen emisores y receptores, tomar en consideración la unidad que nos ocupa obliga a atender, indisociablemente, junto a las cuestiones que tienen que ver con los enunciados, las relativas a la enunciación de dichos enunciados 5 .

Muchos de los problemas que una Linguística del Texto debe abordar no son, por más que esta disciplina tenga una historia relativamente reciente, ajenos a los intereses y preocupaciones de la lingüística pre-textual. Tales cuestiones, sin embargo, sólo pueden ser abordadas desde una perspectiva explicativa plenamente coherente en el seno del nivel que nos ocupa, a no ser con el riesgo indeseable de inevitables interpretaciones erradas sobre su alcance y operatividad exactos.

Es relativamente común, si no una constante inevitable, encontrar en la práctica totalidad de estudios de sintaxis oracional - especialmente en los que podríamos denominar «pre-estructuralistas»-- un capítulo dedicado a la

${ }^{4}$ En la formulación de Teun A. Van Dijk, «...discursos aceptables de la lengua...(que)...están bien formados y son interpretables.». Cfr. T. A. Van Dijk: Texto y contexto, Madrid, Cátedra, 1980, pp: 32 .

${ }^{5}$ Para una primera formulación de los conceptos de enunciación y enunciado. Cfr. E. Benvéniste: Problèmes de linguistique générale, Paris, Gallimard, 1966, pp: 225-285. 
clasificación de las oraciones en el que, junto al estudio de éstas en razón de su estructura gramatical-funcional (personales, transitivas, intransitivas..., etc.), no suele faltar su consideración en atención a lo que se denomina la intencionalidad del hablante o la calidad psicológica del juicio, criterio en virtud del cual las oraciones son, esta vez, clasificadas como exclamativas, de posibilidad, dubitativas, interrogativas, optativas, exhortativas..., etc ${ }^{6}$.

Nada hay que objetar a la coherencia o adecuación de una metodología que en el nivel oracional elabora una tipología de estas unidades que responde a su estructura interna. Sin embargo, el segundo de los criterios manejados es ciertamente problemático por cuanto pudiera inducir a la conclusión de que tales intencionalidad del hablante o calidad psicológica del juicio resultan mecanismos específicamente oracionales. Por aducir un solo ejemplo, la condición «exhortativa» de un enunciado no está necesariamente ligada a característica oracional alguna. Junto a «oraciones exhortativas» como (1i), el mismo tipo de contenidos es encontrable en enunciados de naturaleza gramatical muy diferente como (1ii).

i) ¡Deténgase Vd. ahora mismo!

ii) ¡Stop!

No deja de ser cierto que los mecanismos relacionados con la exhortación pueden tener reflejo en la oración, una de las vías gramaticales para su expresión. Sin embargo, tales mecanismos no son específicamente oracionales, por lo que su estudio debiera ser realizado de forma que, para una lengua histórica específica, fuera puesto de manifiesto el conjunto de posibilidades gramaticales de expresión de tales contenidos comunicativos, que en modo alguno, por lo tanto, se reducen a esa única vía de manifestación oracional.

El problema que el proceder concreto a que venimos refiriéndonos encierra es, pues, doble. De una parte, la inclusión de esta serie de aspectos en la sintaxis oracional puede inducir al error de considerar como especificamente oracionales unos mecanismos cuya verdadera especificidad y sentido se justifican sólo en el nivel textual. De otra, semejante proceder resultaría también escasamente adecuado a la luz de una conceptuación estricta del recurso metodológico de nivel lingüístico, toda vez que dicho concepto implica la determinación, para cada nivel específico, de las características que le son exclusivas, por lo que sería poco coherente metodológicamente aceptar siquiera la posibilidad de integración en un único estadio del análisis de propiedades pertenecientes a dos niveles distintos: el oracional y el textual.

La definición de la unidad texto atendiendo a estos criterios de especificidad funcional permite su individualización, frente a las de los otros niveles linguiísticos,

\footnotetext{
${ }^{6} \mathrm{Cfr}$, a título de ejemplo, S. Gili Gaya: Curso superior de sintaxis española, Barcelona, Spes, 1948, pp: 37-50.
} 
como la menor unidad dotada de independencia o autonomía comunicativa. De esta definición se deduce, por tanto, que lo que llamamos texto es una unidad de carácter semántico, siendo, pues, la dimensión textual independiente de otros factores de naturaleza «gramatical»?. Textos son, así, El Quijote y los enunciados (2), (3) y (4), cuando son interpretados como actos de comunicación con sentido pleno:

(2) ¡Fuera!

(3) Ande yo caliente, ríase la gente

(4) Hace mucho calor

La condición semántico-comunicativa del texto es, sin duda, su propiedad más significativa, que lo distingue del resto de unidades de niveles diferentes, todas ellas conectables con lo que hemos denominado factores de naturaleza «gramatical». Mientras la individualización de un texto depende, en efecto, de su autonomía semántico-comunicativa y de su sentido preciso, la de las unidades del nivel fonemático resultan de su carácter distintivo y del «valor» distintivo concreto en cada caso; la de la unidad palabra de su condición de mínimo espacio de actualización y del tipo de monemas actualizables en cada caso; la de la oración de su condición predicativa específica y de los elementos que en ella intervienen...; factores todos de naturaleza «gramatical», en el sentido propuesto, bien distintos del que determina la condición textual de un determinado enunciado: su sentido pleno.

Esta diferente naturaleza del texto como unidad lingüística hace precisa su inclusión en la jerarquía de niveles lingüísticos en el lugar que le es asignado en (5), que refleja las peculiaridades diferenciales que hemos mencionado y explica el modo particular de articulación ${ }^{8}$ de dicha unidad con las de los restantes niveles.

(5) Jerarquía de niveles linguísticos

v) nivel oracional

$\uparrow$

iv) nivel sintagmático

$\uparrow$

iii) nivel de la palabra

$\uparrow$

ii) nivel monemático

$\uparrow$

i) nivel fono-fonológico

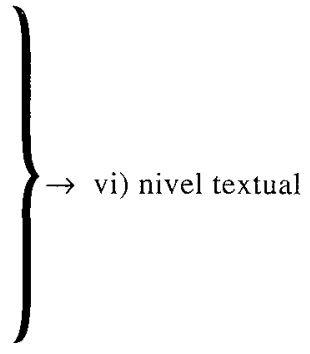

\footnotetext{
${ }^{7}$ Utilizamos el término «gramatical» en sentido amplio, en referencia al nivel fono-fonológico, monemático, de la palabra, sintagmático y oracional, incluyendo los distintos componentes necesarios para su estudio; en sentido semejante al que es habitual, por ejemplo, en la lingúistica generativo-transformacional.

${ }^{8}$ Utilizamos el concepto martinetiano de articulación en el sentido propuesto por G. Rojo: «En torno al concepto de articulación», Verba, 9, 1982, pp: 5-40. En sentido estricto, la relación entre el componente fono-fonológico y el monemático quedaría fuera de dicho concepto en formulaciones
} 
La representación establecida en (5), y el lugar que en ella se asigna a la unidad texto, pretenden reflejar la naturaleza peculiar de dicha unidad frente a las de los restantes niveles lingüísticos; fundamentalmente el hecho de que el nivel textual no constituye un estadio más en la jerarquía de niveles gramaticales (i-v), resultando así el nivel jerárquicamente más «elevado» o complejo - lo que supondría su localización en la escala jerárquica en el lugar asignado en (5a) - . Mientras que las relaciones de articulación que tienen lugar entre fonemas y monemas, monemas y palabras, palabras y sintagmas y sintagmas y oraciones son, en efecto, las previstas en (5) o (5a): prototípicamente pueden asumirse como relaciones de constitución representativas y habituales las de cada unidad de un nivel «n» por unidades del nivel jerárquicamente inferior «n- 1 », no sucede lo mismo con las unidades que caracterizamos como textos. Estas no articulan —o están constituidas por- oraciones, pudiendo, al contrario, materializarse a través de unidades de cualesquiera de los niveles (i-v). Un texto del contenido de (6) puede, así, tener las manifestaciones de (6i-v), que coinciden con los distintos niveles «gramaticales» mencionados. Ello pondría de manifiesto el lugar exacto que corresponde a la unidad que nos ocupa en el conjunto más general de las unidades lingüísticas, el de unidad virtualmente instrumentalizadora de las unidades «gramaticales» de no importa qué nivel, que son rentabilizadas en el ámbito textual con la única exigencia de que sirvan a la expresión del sentido característica de éste.

(5a)
vi) nivel textual
$\uparrow$
v) nivel oracional
$\uparrow$
iv) nivel sintagmático
$\uparrow$
iii) nivel de la palabra
$\uparrow$
ii) nivel monemático
$\uparrow$
i) nivel fono-fonológico

(6) A ordena a B callarse

i) ¡tssss...!

iii) (Silencio!

iv) ¡Esa boca...!

v) Te ordeno que te calles.

como la de Hockett para quien la relación entre estos dos niveles es de representación. Cfr. Ch. F. Hockett: Curso de lingüística moderna, Buenos Aires, Eudeba, 1971, pp; 135-136. 
El ámbito de lo que denominamos texto es, pues, el de la producción de sentido; producción que, en el caso de las diferentes lenguas naturales, se logra mediante la dinamización, pertinentización o rentabilización de su código gramatical (5i-v) al servicio de esta función esencialmente comunicativa, que introduce, por consiguiente, como factores esenciales de lo textual las figuras del emisor y receptor, o, lo que es lo mismo, los mecanismos de la enunciación. Todo texto es la enunciación de un enunciado.

La caracterización tipológico-lingüística de una clase de textos como los constitucionales ha de basarse, entre otros aspectos, en los relativos a su contenido proposicional/ilocutivo específico $0^{9}$, así como en la determinación de sus elementos estructurales distintivos. Ello, naturalmente, sin olvidar que, tanto estos dos aspectos, como cualesquiera otros que puedan ser considerados nunca podrán ser abordados como una mera suma de factores de idéntico valor, toda vez que el texto, como cualquier unidad de un nivel lingüístico determinado, es una gestalt, un conjunto o totalidad cuyo valor no es simplemente producto del de sus elementos constituyentes, sino que, al contrario, posee determinados valores organizativos específicos de la totalidad que gobiernan, precisamente, las posibilidades de las partes para ser aceptadas como constituyentes del todo. Respecto de las dos series de cuestiones mencionadas, por tanto, es preciso asumir que el contenido proposicional/ilocutivo de los textos constitucionales resulta determinado por la estructura general de éstos, que no sólo condiciona una cierta organización estructural, sino también el mismo tipo de contenidos semánticos aceptables para este tipo de textos.

La atención al contenido proposicional/ilocutivo de los textos que conocemos como constituciones es útil como rasgo identificador. Se trata de textos que desarrollan las bases de organización de una comunidad de seres humanos que, en este sentido, «constituyen». Son, pues, textos ilocutivamente fundadores de un estado de cosas, de un mundo posible cuya identidad descansa sobre el conjunto de principios enunciados.

Los textos constitucionales que estudiamos encuentran en esta su función ilocutiva una especificidad que les diferencia claramente de otros muchos tipos de finalidades pragmáticas. Sin embargo, comparten esta misma propiedad con buen número de otros textos «constitucionales», de mayor o menor alcance colectivo. Textos «constitucionales», fundadores o creadores de situaciones o entidades, son también aquellos que organizan fundaciones, empresas, comunidades de vecinos, y también los textos orales que es posible escuchar en boca de los niños que, decidiendo la naturaleza de sus juegos ocasionales en una tarde, fijan una modalidad, sus reglas elementales y el papel concreto de cada uno de los participantes. Frente a tales prácticas «constitucionales», los Textos Constitucionales ${ }^{10}$ que nos ocupan se caracterizan claramente por

\footnotetext{
"Cfr. John Searle: Speech Acts, London, Cambridge U. P., 1969, pp: 42.

${ }^{10}$ En lo sucesivo, «TTCC».
} 
poseer una carácter colectivo de mayor alcance y por su condición políticosocial; por fundar un universo de relación social que afecta a toda una colectividad nacional en los términos de su misma condición de miembros de dicha colectividad.

Esta primera y evidente nota distintiva es, como indicábamos, indisociable de la organización estructural de los TC.

La condición «textual» de un determinado acto lingüístico le viene siempre a éste de ser la manifestación de una organización estructural, siempre diferente de dicha manifestación, que inevitablemente coincidirá, en el caso de los textos producidos a través de sistemas semióticos que son lenguas naturales, con unidades de los niveles gramaticales (5i-v).

La descripción de la organización estructural de un texto hace necesario contar con dos niveles globales de estructuración distintos, uno de los cuales es imprescindible para la existencia de la textualidad misma: el de la macroestructura textual"!

El plano de la macroestructura textual constituye el estadio de su representación estructural que coincide con las informaciones semánticas esenciales transmitidas por el texto, su organización semántico-comunicativa medular.

La macroestructura, como elemento de la estructura del texto, es distinta de su manifestación o microestructura. Su vinculación es explicada a través de reglas u operaciones como las establecidas por Teun A. Van Dijk, concebidas como procedimientos para la reducción de la información semántica ofrecida en la microestructura a los contenidos informativos esenciales de la macroestructura. Estas reglas pertenecen a cuatro tipos ${ }^{12}$ : de omisión, que operan mediante la cancelación de informaciones no relevantes, posteriormente irrecuperables —es el caso de la macroestructura (7), correspondiente a la microestructura ( $7 \mathrm{i}$ ) —; de selección, que reducen la complejidad de informaciones microestructurales que, sin embargo, pueden ser recuperadas por estar en relación de presuposición, consecuencia o ser parte integrante de la información macroestructural seleccionada -así sucede con la relación entre la macroestructura (8) y la microestructura de (8i)—; de generalización, que instauran en la macroestructura una información que es la superordenada de la de la microestructura correspondiente - como sucede con (9) respecto de (9i) - y de construcción o integración, que globalizan en la macroestructura informaciones de la microestructura —es lo que acontece respecto de la microestructura (10i) en la macroestructura (10)-.

(7) Aparcó el coche.

(7i) Aparcó el coche. El coche era grande y amarillo.

${ }^{11}$ Cfr. T. A. Van Dijk: La ciencia del texto, Barcelona, Paidós, 1983, pp: 54 y ss., además del ya cit. Texto y contexto, pp: 1 y ss. Del mismo autor: «Nota sulle macrostrutture linguistiche», en Maria Elisabeth Conte (ed.): La linguistica testuale, Milán, Feltrinelli, 1977, pp: 181-194.

${ }^{12}$ Cfr. T. A. Van Dijk: La ciencia del texto, cit., pp: 59-63. 
(8) Andrés aparcó su coche.

(8i) Andrés llegó a un lugar, paró su coche y lo aparcó.

(9) En la calle había varios vehículos.

(9i) En la calle había coches, camiones y autobuses.

(10) Cogí el tren.

(10i) Fui a la estación, compré un billete, me acerqué al andén, subí al tren y éste partió.

Las citadas reglas son, ciertamente, mecanismos capaces de explicar las conexiones semánticas que vinculan a macro y microestructuras. Sin embargo, son parte de un simulacro de funcionamiento textual que sólo puede ser considerado aceptable desde la perspectiva del receptor.

En todo modelo semiótico la organización o sistematización de la competencia que gobierna la realidad considerada puede/debe realizarse desde la doble perspectiva de la emisión o la recepción. Ambas, aunque consideradas en algunos modelos lingüísticos como equivalentes ${ }^{13}$, suponen una muy distinta perspectiva que conlleva, en cada caso, problemas de naturaleza muy diferente.

En el ámbito en que nos movemos, el análisis de los textos no es en modo alguno indiferente respecto de la perspectiva elegida. Para la de su recepción es perfectamente posible imaginar la existencia de receptores de condición diferente, en los extremos de una escala imaginaria, receptores especializados y receptores comunes. Sólo para los primeros puede ser lícito suponer la existencia de los mismos mecanismos de competencia postulables para la producción del texto de que se trate, en nuestro caso de un TC; identidad de mecanismos que no impide, sin embargo, la posible existencia de lecturas parciales de un TC por parte de un receptor especializado. Las cosas son naturalmente distintas cuando consideramos la relación TC-receptor común. Para éste, para quien siempre será posible también una lectura parcial del texto, es patente la inadecuación de suponer una competencia de recepción en todo idéntica a la de la producción/ emisión del TC; dicho en otras palabras, el mismo tipo de conocimiento «técnico» o competencia que permite a los productores canónicos de un TC su emisión.

La perspectiva que guía nuestra aproximación tipológica a los TTCC es la de su producción/emisión. Aunque, como indicamos, una sólo de aquéllas desde la que pueden ser considerados, se trata sin duda de la perspectiva desde la cual ha de ser posible la caracterización tipológica más representativa de esta clase de textos; aquélla desde la que los TC pueden ser definidos prototípicamente ${ }^{14}$; es decir, como tipo textual más claramente diferente de otros tipos pertenecientes a clases distintas.

\footnotetext{
${ }^{13}$ Así sucede explícitamente en Noam Chomsky: Aspectos..., cit., pp: 10.

${ }^{14}$ Para una presentación general de la denominada «teoría de prototipos», véase nuestro trabajo «Aspectos prototípicos en la categorización lingüística», en Studi Orientali e Linguistici, III, Bolonia, C.L.E.B., 1986, pp: 269-279.
} 
Desde la perspectiva de su emisión, es claro que reglas como las enunciadas por Van Dijk son escasamente útiles para reflejar la conexión existente entre macroestructuras y microestructuras textuales. Tales reglas, en efecto, como reglas de «reducción» de información semántica que son, reflejarán el modo de proceder de la competencia receptora, que enfrentada a la microestructura de los textos ha de reducir la diversidad de informaciones superficiales para llegar a la macroestructura textual, a su contenido comunicativo esencial. Desde la perspectiva de su emisión, la relación macroestructura-microestructura textual es, naturalmente, otra: no se trata de una relación de carácter reductivo o sintético, sino, al contrario, analítico; del recorrido, contrario al anterior, que va de lo único a lo múltiple. Así pues, parece obligado considerar para el punto de vista que nos interesa reglas de conexión entre macroestructuras y microestructuras textuales que habrán de ser, lógicamente, las opuestas a las postuladas por Van Dijk; frente a (11), las reglas de reducción por él establecidas, las de (12) que podrían ser caracterizadas por presentar propiedades distintivas generales antitéticas a las de (11), pero con la operatividad analítica propia de su carácter de mecanismos que tienen que ver con la competencia emisora textual.

(11)

$\begin{array}{cccc}\text { omitir } & \text { seleccionar } & \text { generalizar } & \text { construir } \\ \text { vs } & \text { vs } & \text { vs } & \text { vs }\end{array}$

(12)

añadir desarrollar particularizar deconstruir

Entenderemos, pues, que, desde la óptica de la producción de un texto, dada una macroestructura como (7), ésta puede ser conectada/analizada en una microestructura como (7i) mediante operaciones de «añadido», caracterizadas por la no vinculación lógica de los contenidos añadidos para con los correspondientes de la macroestructura.

Como «desarrollo» proponemos la operación analítica de transformación de una macroestructura en su microestructura correspondiente, que constituye el contradictorio de la «selección»: el paso de (8) a (8i), que se caracteriza por la existencia de fuertes relaciones de conexión lógica entre ambos planos, de manera que los aspectos desarrollados en la microestructura mediante esta operación estarían vinculados a la macroestructura correspondiente por presuposición, consecuencia, etc.

Denominamos «particularización» al análisis de una macroestructura en la microestructura correspondiente cuando aquélla es el superordenado lógico de ésta, que, por tanto, resulta su «particularización». Es el caso de (9i) respecto de (9).

Proponemos el término «deconstrucción» como contradictorio lógico de la correspondiente operación en el plano de la recepción textual; como denominación de una operación que para una macroestructura dada analizará ésta en los 
elementos constitutivos propios de un determinado marco o esquema ${ }^{15}$ conceptual, tal y como sería el caso de la relación entre (10) y (10i).

La macroestructura de un texto puede ser descrita en forma de macropoposiciones, cuya estructura podemos representar, en la forma habitual en semántica, mediante la articulación de Predicados, Actantes y Circunstantes ${ }^{16}$; los primeros, elementos no sustantivos de las macropoposiciones denotadores de estados/procesos dinámicos y no dinámicos; los segundos, correspondientes a entidades sustantivas que presentan un grado de dependencia fuerte respecto de los predicados, y los circunstantes que mantienen respecto de aquéllos una vinculación más exterior.

La estructura interna de las macroproposiciones está determinada por una serie de relaciones sintácticas que, como en toda unidad susceptible de la operatividad de tales relaciones, han de ser analizadas desde dos puntos de vista; diferenciando entre su comportamiento como categorías y como clases de relaciones sintácticas ${ }^{17}$

Considerar el comportamiento de las relaciones sintácticas macroproposicionales como categorías supone plantear su estudio en atención a las relaciones que, como partes o constituyentes de un todo, mantienen para con él; atender a las relaciones sintácticas macroproposicionales que son obligatorias $\mathrm{o} / \mathrm{y}$ opcionales para la existencia del constituto macroproposición.

En los TTCC iberoamericanos encontramos los tres tipos de esquemas macroestructurales siguientes:

(13i) Un Emisor (presidente) Enuncia (hace saber) a un Destinatario (el país) en un Tiempo y Lugar que ${ }^{18}$ por una Causa determinada (preámbulo) un Emisor (asamblea constituyente) Enuncia (promulga) un Objeto (constitución) a un Destinatario (el país) en un Tiempo y Lugar ${ }^{19}$.

(13ii) Por una Causa determinada (presentación, preámbulo) un Emisor (presidente,asamblea constituyente) Enuncia (decreta, sanciona, proclama) un Objeto (constitución) a un Destinatario (el país) en un Tiempo y Lugar ${ }^{20}$.

Simplificadamente, la macroestructura de estos TTCC obedece a dos esquemas estructurales de diferente complejidad: de enunciación compleja en (13i) —véase (13ia)—, y de enunciación simple en (13ii) — véase (13iia)—.

(13ia)

Emis. Enunc. Obj. (Emis. Enunc. Obj. Destinat. Tpo. Lug. Causa) Destinat. Tpo. Lug.

${ }^{15}$ Cfr. Charles J. Fillmore: «An alternative to Checklist Theories of Meaning», in Proceedings of the First Annual meeting of the Berkeley Linguistic Society, B.L.S., 1975, pp: 124.

${ }^{16}$ Utilizamos estas categorías en el sentido propuesto por A. J. Greimas: Semántica estructural, Madrid, Gredos, 1973, pp: 236 y ss.

${ }_{17}$ Para tal distinción, véase nuestro trabajo Las construcciones pronominales pasivas e impersonales en español, Murcia, Universidad, 1990, pp: 34-58.

${ }^{18}$ La proposición introducida mediante «que» constituye el objeto del predicado «hace saber».

${ }^{19}$ A tal esquema responde, por ejemplo, la constitución de Nicaragua (1986).

26 A este esquema responden las constituciones de El Salvador (1983), Filipinas (1986), Puerto Rico (1917), Chile (1980), México (1917) y Portugal (1976). 


\section{(13iia)}

Emis. Enunc. Obj. Destinat. Tpo. Lug. Causa

Ambos esquemas macroestructurales resultan de la distinta organización política de las comunidades de que emanan los TTCC. En el primer caso -(13i) - , lo que denominamos «texto constitucional» es un acto discursivo que emana de un enunciador distinto de la Asamblea Constituyente. Éste garantiza o autentifica en un momento temporal dado y en un lugar preciso —el del país correspondiente-, para los ciudadanos de dicho país, el mecanismo de enunciación de la Asamblea Constituyente que crea, produce o enuncia para unos destinatarios precisos (los ciudadanos del país de que se trata) unas normas constitucionales en una fecha y lugar precisos y por unas razones o motivaciones dadas.

En el caso de (13ii) se produce una enunciación directa por parte de una Asamblea Constituyente que enuncia un objeto -texto constitucional- a unos destinatarios (los ciudadanos del país) en un tiempo y lugar dados, y con una motivación determinada.

Prescindiendo de la posible complejidad sintáctica derivada de los mecanismos de recursividad en la macroestructura constitucional, la fórmula macroproposicional elemental de los TTCC sería, pues, la representada en (13iii):

(13iii) Emis./Sujeto Enunc. Obj. Destinat. Tpo. Lug. Causa

Desde la perspectiva categorial que mencionábamos, las relaciones sintácticas de tales elementos obedecen al esquema representado en (14):

Macroproposición

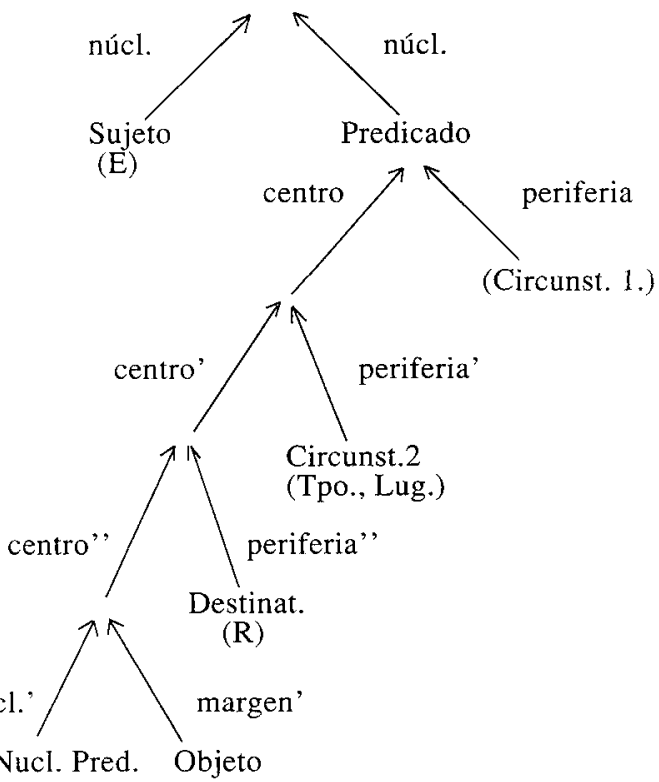


(14) esquematiza, por tanto, las relaciones sintácticas macroproposicionales desde la perspectiva categorial; es decir, atendiendo a las relaciones de dependencia funcional que, como constituyentes de la unidad «macroproposición» establecen para con dicho constituto. Ello explica los valores asignados en el esquema a cada uno de los elementos.

Como indicamos, la unidad «texto» resulta de la dinamización del sistema «gramatical» de una lengua cuando es utilizado para la producción de intercambios comunicativos por emisores y receptores. Se desprende de ello automáticamente que las figuras actanciales de Emisor y Receptor, y los papeles funcionales que a ellos corresponden, son papeles nucleares de la macroproposición, relaciones sintácticas sin cuyo concurso no existe una estructura textual bien formada ( $\mathrm{si}$ bien en los intercambios comunicativos orales y estandarizados estas figuras puedan ser elididas por ser sobreentendidas). De los dos papeles actanciales citados, el correspondiente al emisor debe ser situado al mismo nivel que el predicado macroproposicional toda vez que se trata de la figura actancial que funciona, precisamente, como enunciador, es decir, como sujeto de la enunciación.

El predicado macroposicional es un elemento/relación complejo. Como en el ámbito gramatical-oracional, los distintos elementos que de él forman parte no pueden ser representados como un conjunto sujeto a meras relaciones de composición, lo que equivaldría a postular para ellos exactamente el mismo tipo de relación para con el núcleo predicativo. Al contrario, la vinculación de los diferentes elementos actanciales y circunstanciales del predicado para con su núcleo supone grados diferentes de conexión.

Dentro del Predicado es preciso establecer una categoría de relación específica, que denominamos Circunstancial- $I$ de forma absolutamente provisional, para dar cuenta del hecho de que determinados constituyentes macroproposicionales se comportan de modo claramente periférico respecto del resto de constituyentes del predicado. Es lo que sucede con las funciones circunstanciales de causa, concesión... en macroproposiciones como (15) o (16), correspondientes, respectivamente, a la organización textual simplificada de las microestructuras (15i) y (16i):

(15) Emisor(x) enuncia $Y$ a un Receptor(z) por la Causa(w)

(15i) ¡Harás eso porque yo lo digo!

(16) Emisor(x) enuncia Y a un Receptor(z) a pesar de W

(16i) Aunque el suelo está mojado no ha llovido

La función que estas informaciones desempeñan como constituyentes de la macroestructura textual es, además de la de elementos opcionales —de ahí su notación entre paréntesis- viene a ser la de la relación más alejada del núcleo predicativo de cuantas forman parte del predicado ${ }^{21}$. De ahí su consideración

${ }^{2 \mid}$ Para las distintas pruebas mcta-gramaticales que muestran la adecuación de esta definición, Cfr. Agustín Vera Luján-María Luisa Masiá Canuto: «La categoría de función «complemento circunstancial» en español», Voz y letra, 2, 1991, (en prensa). 
como periferia, en el sentido que el término posee en la Escuela de Praga: miembro de una estructura o sistema, aunque en grado menor que otros elementos que serían su centro ${ }^{22}$.

Dentro del predicado macroestructural, y de las relaciones centrales, es necesario distinguir un nuevo bloque de relaciones periféricas', papel funcional que caracteriza al conjunto de los que denominamos, con la misma intención de mera provisionalidad ya destacada para el caso anterior, Circunstancial-2. Dicha categoría se propone como englobadora de las indicaciones macroestructurales de tiempo y lugar propias de todo texto. Dichas categorías son obligatorias, a diferencia de las anteriores, pues la emisión de cualquier texto implica necesariamente las coordenadas deícticas del presente de su producción y del espacio-aquí de su productor. Tales indicaciones deícticas son, en términos generales, elidibles para el caso de textos comunes, los textos propios de una relación comunicativa estándar: oral y con co-presencia de emisor y receptor o receptores, característicamente marcados por el «presente» y el «aquí».

La de Circunstancial-2 es una relación definida como periférica' dentro del conjunto de relaciones que denominamos centro' por su condición de función menos estrechamente vinculada con el núcleo predicativo que el resto de las representadas en los nudos inferiores del diagrama $(14)^{23}$.

Obligatoria es también la presencia de la categoría de función macroestructural destinatario, como correspondiente al papel sintáctico que cumple al receptor o enunciatario textual; figura sin la que difícilmente pudiera ser considerado el texto como la unidad de comunicación que es. Su papel específico es caracterizado en (14) como periferia", indicándose así una vinculación mayor para con el núcleo predicativo que la de los denominados «circunstancial- $1 »$ y «circunstancial$2 »$, pero menor que la que el objeto macroproposicional mantiene para con aqué ${ }^{24}$.

Por último, bajo el nudo centro' 'se acogen las funciones macroproposicionales núcleo predicativo y objeto, directamente vin vinculadas y obligatorias ambas ${ }^{25}$ : ni es posible la existencia de un texto bien formado del que falte el hecho de enunciar, ni lo enunciado.

\footnotetext{
${ }^{22}$ Cfr. F. Danes: «The Relation of Centre and Periphery as a Language Universal», Travaux de Linguistique de Prague, 2, 1966, pp: 9-22.

${ }_{23} \mathrm{La}$ más directa vinculación de los circunstanciales-2 respecto del núcleo predicativo proposicional - en relación con la de los circunstanciales- $I$ - puede ser comprobada a la vista de lo que sucede en enunciados como Antonio veranea en Málaga porque tiene una casa allí, expandible con y yo lo hago también porque la alquilo, pero no con el agramatical ts yo lo hago también en Almeria. La agramaticalidad del último enunciado provendría de la proverbialización de un elemento proposicional como circunstanciall sin que afectara, como sería obligatorio, a los elementos menos periféricos que éste.

${ }^{24}$ Mientras que el destinatario puede ser proverbializado o dejado al margen de este mecanismo (Antonio escribió una carta a sus amigos y yo lo hice también y yo lo hice a los míos), nunca puede ser dejado fuera del ámbito de la proverbialización si ésta afecta a un elemento/relación regido por un mayor grado de periferia: *Antonio escribió una carta a sus amigos desde Barcelona y yo lo hice a los míos.

${ }^{25}$ El objeto no puede ser separado del núcleo proposicional. Véase la agramaticalidad de *Antonio escribio una carta y yo lo hice una postal.
} 
Las relaciones que representamos en (14) delimitan, así, la imagen categorial de la macroestructura de un texto como una serie de relaciones virtuales de determinación - en su abrumadora mayoría obligatorias - sucesivas, tal y como puede mostrarse también en (17):

(17)

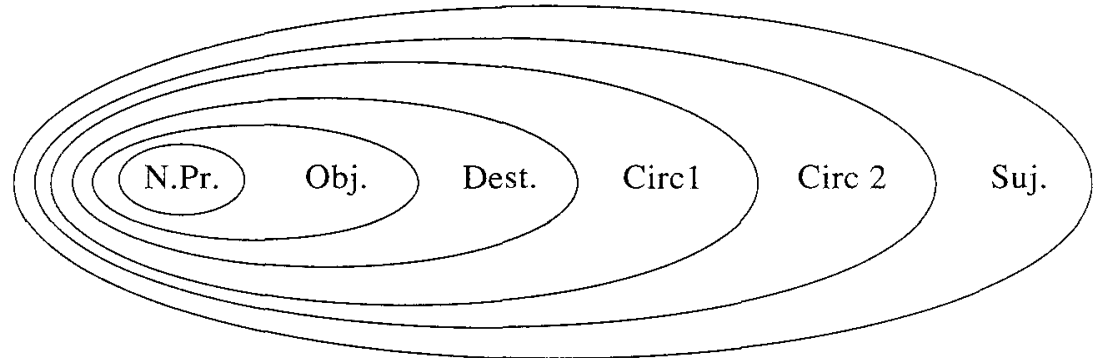

Tras estas consideraciones generales sobre la naturaleza y funcionamiento metalingüísticos del plano de la macroestructura textual es posible obtener algunas - aunque mínimas - características tipológicas definitorias de los TTCC. Estos, como todos los textos escritos, presentan la nota distintiva, en lo categorial, de la imposibilidad de elisión de las indicaciones relativas a su emisor y receptor. Dicha particularidad resulta explicable para discursos en los que no se da, como en el caso de los estandarizados orales, la co-presencia inmediata y no sujeta a ambiguiedad de emisor y receptor, por lo que tales figuras - salvo en textos de naturaleza especial, como los literario- - han de ser precisadas con exactitud.

Desde el punto de vista categorial los TTCC no presentan ninguna otra particularidad. Ello es lógico puesto que, desde esta perspectiva, las cuestiones consideradas no son sino aquellas que garantizan a un texto determinado la condición de texto; condición que no puede estar basada sino en mecanismos de naturaleza muy general: los propios de la unidad como tal. Desde esta perspectiva la estructura categorial de los TTCC puede formalizarse, como ya indicábamos, en una macroproposición básica como (13iii):

(13iii)

Suj.-Emis. Enuncia Obj Dest.-Recep. Tpo. Lug. Causa

Las peculiaridades de los TTCC, en el plano estructural, han de ser buscadas en la dimensión de clases de sus relaciones funcionales constitutivas.

Caracterizar las relaciones sintácticas de una unidad atendiendo a la perspectiva mencionada supone adoptar un punto de vista distinto al mantenido hasta ahora; interesado esta vez, no ya en las relaciones que un determinado constituyente establece para con el constituto de que forma parte; es decir, en las relaciones de una parte para con el todo del que es constituyente, sino en las 
relaciones posibles de cada una de esas partes/constituyentes para con otras también constituyentes de esa unidad/constituto. Frente a la naturaleza de las relaciones categoriales, representable en la forma de (18), la propia de las clases será, por tanto, la reflejada en (19).

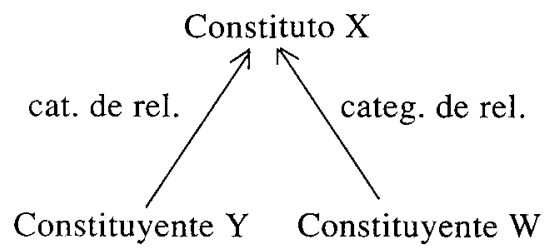

(19)

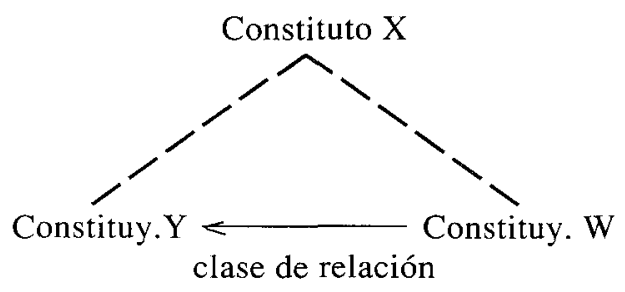

La caracterización de la estructura sintáctica macroproposicional requiere la atención a las dos perspectivas de análisis mencionadas. La especificidad de un tipo textual determinado será resultado directo de sus clases de relaciones sintácticas. Estas, sin embargo, no son nunca independientes de una determinada identidad categorial; es decir categorías y clases de relaciones sintácticas son solidarias desde el momento en que ninguna categoría de relación puede manifestarse sin pertenecer a una clase específica, ni clase alguna de relación puede concurrir macroproposicionalmente sin ser una clase respecto de una categoría de relación. La distinción entre ambas perspectivas es, sin embargo, imprescindible metodológicamente y entraña importantes consecuencias para la correcta comprensión de la operatividad sintáctica de las distintas unidades linguísticas.

Diferenciar, para una determinada unidad, entre sus categorías y clases de relaciones sintácticas es la única vía para evitar inadecuaciones explicativas como las que, a título de ejemplo, son frecuentes en el ámbito de la sintaxis oracional respecto de la distinción entre elementos/relaciones actanciales y circunstanciales. En virtud de la condición «marginal» de los segundos, como se advierte en oraciones del tipo de (20), en la que el sintagma en función de complemento circunstancial es eliminable — véase (20i)—, suele negarse a sintagmas semejantes en estructuras oracionales similares la condición de 
complemento circunstancial cuando no pueden ser eliminados ${ }^{26}$-véanse (21) y (21i)-.

(20) Andrés hace deporte en verano

(20i) Andrés hace deporte

(21) Andrés reside en Baracaldo

(21i) *Andrés reside

Un problema semejante podría suscitarse para la caracterización de las relaciones sintácticas propias de la macroestructura textual en el caso de utilizar un recurso metalingüístico como el concepto de función/relación sintáctica sin diferenciar entre su dimensión de categoría o clase. Sin tal diferenciación, en efecto, y atendiendo por tanto al estudio de las relaciones funcionales en la forma en que éstas suelen generalmente ser caracterizadas, resultaría problemática la asignación a la indicaciones de tiempo y lugar de los TTCC de la función de circunstanciales, y lo sería también, por otras razones, la consideración como tales de las indicaciones de causa que incluíamos bajo la categoría de circunstancial-1.

La conceptuación de las indicaciones de tiempo y lugar como circunstancial2 plantearía el problema de considerar como tal a una serie de informaciones cuya existencia es obligatoria en cualquier texto estándar, cuya macroestructura, como veíamos, necesariamente incluye las referencias deícticas del presente y aquí de la enunciación. Si tales indicaciones resultan, pues, obligatorias para la gramaticalidad de un texto, que careciendo de ellas sería anómalo, estas peculiaridades funcionales vendrían a estar reñidas con la característica aparentemente definitoria de los circunstanciales o circunstantes en la práctica totalidad de aproximaciones metalingüísticas a estos fenómenos; con su característica eliminabilidad.

Las indicaciones macroproposicionales de tipo causal, caracterizadas por nosotros como en función de circunstancial- 1 plantearían, por su parte, otros problemas. Tal relación funcional es opcional, desde la perspectiva categorial, para la existencia del texto; es decir, es una relación cuyo elemento representativo no es imprescindible para la macroestructura textual. Sin embargo, no es menos cierto que, para un tipo de texto específico, el TC, estas indicaciones, y, por consiguiente, la función sintáctica por ellas desempeñada no es en modo alguno prescindible: todo TC presenta obligatoriamente esta relación funcional como una de las características estructurales que lo singularizan como tal tipo de texto.

Hechos de esta naturaleza llevarían a las aproximaciones sintácticas al uso a

${ }^{26} \mathrm{Cfr}$. al respecto, G. Rojo: «En torno a los complementos circunstanciales», Lecciones del I y II Curso de Lingüística Funcional (1983 y 1984), Oviedo, Universidad, 1985, pp: 181-191, y E. Alarcos Llorach: «Prólogo» a H. Martínez García; El suplemento en español, Madrid, Gredos, 1986 , pp: $3-5$. 
concluir en el sentido de la no condición de circunstanciales de las relaciones que hemos conceptuado como circunstancial-1 y circunstancial-2, para las que se deberían establecer denominaciones que recogieran su supuesta condición de invariantes funcionales distintas de las restantes consideradas. Con ello se incurriría en una doble inadecuación. De un lado, se perdería de vista que, opcionales o no, dichas relaciones tienen, desde el punto de vista de las conexiones que establecen para con la unidad-constituto de que forman parte, exactamente el mismo tipo de funcionamiento: el de elementos/relaciones que constituyen la periferia o periferia' macroproposicional. De otro lado, se habría instalado en el componente sintáctico así esbozado una perspectiva incoherente con los planteamientos sostenidos para el estudio de otros niveles lingüísticos, especialmente en lo relativo al componente sintáctico de la unidad palabra, cuyo análisis, sorprendentemente, parece haber escapado felizmente a estos problemas.

La estructura sintáctica de la unidad palabra es objeto de una caracterización generalizada $^{27}$ según la cual las relaciones sintácticas que operan en su seno son conceptuadas desde dos puntos de vista. Desde el primero, los monemas que son sus constituyentes inmediatos se caracterizan como elementos que desempeñan funciones nucleares, (lexemáticas), o marginales (morfemáticas), desde un punto de vista por consiguiente que es equivalente al que venimos denominando categorial, y que podríamos representar esquemáticamente como (22). Paralelamente, sin embargo, el análisis sintáctico de dicha unidad no se agota en esta caracterización, sino que atiende también a una perspectiva distinta; centrada esta vez, no ya en las relaciones sintácticas de los monemas constitutivos de la palabra para con dicho constituto, sino en las relaciones que un determinado monema-constituyente guarda para con otros. En virtud de estos nuevos planteamientos resultan los distintos tipos monemáticos: sustantivos, adjetivos..., etc., que son producto, pues, de unos criterios de definición que proceden de una perspectiva en todo semejante a la que venimos denominando de clase -vid. (23) - Sólo por ello es lógico no encontrar, a propósito de la caracterización de la estructura sintáctica de una palabra como niño, observación alguna sobre la no condición de función morfemática de la desempeñada por el monema -o. $\mathrm{Si}$, en efecto, una distinción semejante a la que hemos establecido entre categorías y clases de funciones no hubiera sido tomada en cuenta en este ámbito, dada la no eliminabilidad de - $o\left({ }^{*}\right.$ niñ-), difícilmente la función sintáctica que desempeña podría haberse conceptuado como morfemática.

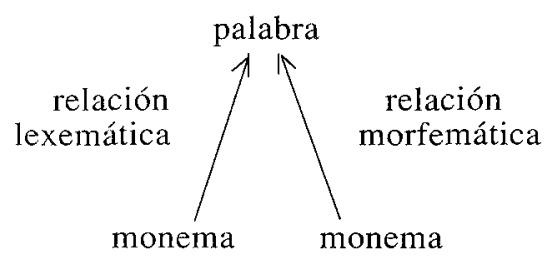

${ }^{27}$ Véase al respecto nuestro ya cit. Las construcciones pronominales..., pp: 31 y ss. 


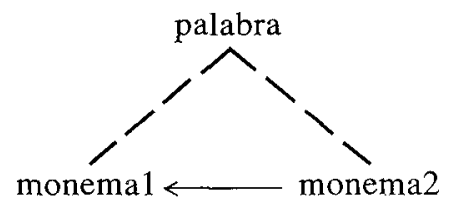

clase de relac. $x$

En el nivel del texto, la distinción entre categorías de relación y clases de relación es, no sólo metodológicamente necesaria, sino sumamente relevante desde un punto de vista tipológico. Gracias a ella podremos dar cuenta de modo adecuado del estatuto particular de alguno de los que denominamos circunstancial1 , especialmente del causal. Dicho circunstancial- 1 constituye un elemento/ relación perfectamente prescindible, como categoría, desde el punto de vista de la existencia del texto como tal unidad. Seleccionada en la producción de un texto dicha relación, su obligatoriedad u opcionalidad dependerá ya del resto de constituyentes textuales con los que se combina. En el caso de los TTCC tal elemento/relación opcional devendrá obligatorio.

La causalidad, incardinada en la relación sintáctica circunstancial-1, es así un factor tipológicamente distintivo de los TTCC que presentan, por consiguiente, una constante macroprosicional semejante a lo que se ha denominado, en el nivel oracional, causa de enunciación ${ }^{28}$. Esta, en función de circunstancial-l obligatorio en los TTCC, es operativa, en los casos de enunciación recursivamente compleja, tan sólo en la enunciación dominada - (13i)-.

La perspectiva que denominamos de clase resulta útil para caracterizar otros aspectos distintivos de los TTCC. Así sucede con los papeles macroestructurales de Emisor y Receptor de estos textos, cuyas identidades están estructuralmente fijadas por el mismo tipo textual, de forma que ambos están sujetos a una especie de relación de reflexividad: los Emisores son una parte del grupo de Receptores a que va dirigido/obliga el TC, aunque han de reunir los requisitos políticos exigidos para el adecuado desempeño de esta función: han de ser legítimos representantes de los receptores textuales.

La consideración de las funciones macroproposicionales como clases no descansa tan sólo en estos aspectos de naturaleza semántico-textual, que determinarían el establecimiento de otras tantas clases semánticas. Las restricciones a que los constituyentes de un texto están sometidos por su combinatoria con otros en el seno de un tipo textual específico abarcan por igual al resto de componentes lingüístico-textuales, y característicamente tienen su reflejo en la misma dimensión formal de los constituyentes macropropo-

${ }^{28}$ Cfr. R. Lapesa: «Sobre dos tipos de subordinación causal», in Estudios ofrecidos a Emilio Alarcos, 3, Oviedo, 1978, pp: 173-205, y E. Ramón Trives: Estudios sintáctico-semánticos del español l. La dinámica interoracional, Murcia, Godoy, 1982. 
sicionales. Es el caso del elemento/relación que hemos denominado objeto, la «constitución» ${ }^{29}$ misma, característicamente complejo, equivalente a toda una serie de macroproposiciones. Esta complejidad es lógica tratándose, como sucede con los TTCC, de textos de una considerable complejidad, que instituyen, $o$, mejor, constituyen, todo un marco o esquema en el que se pretende estructurar la vida de una sociedad en todos sus aspectos fundamentales.

Respecto del grado mismo de complejidad de organización del objeto«constitución» desde el punto de vista macroproposicional, pueden establecerse en los TTCC iberoamericanos tres grados distintos. Un grado mínimo estaría representado por Constituciones como la de Puerto Rico, texto cuyo objeto macroproposicional está constituido, a su vez, por una única serie compuesta de macroproposiciones, estableciéndose, pues, una única jerarquía simple de relaciones de dominio, según podemos representar en (24):

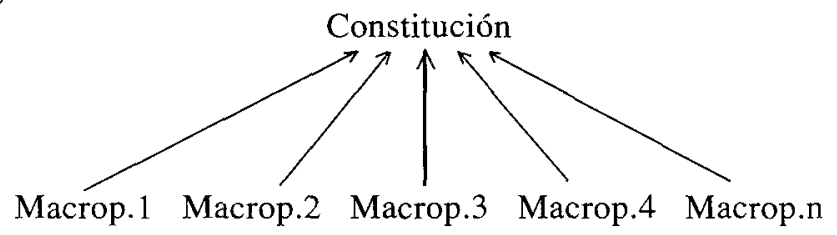

La Constitución de Puerto Rico, en efecto, presenta un grado mínimo de complejidad macroproposicional, resultado de su organización en un único estadio ulterior de bloques temático-macroproposicionales (correspondientes a otros tantos artículos), que no son objeto de posteriores análisis semánticotemáticos.

TTCC como el de Nicaragua muestran un grado intermedio de complejidad en la estructuración del objeto textual. Éste domina dos estadios inferiores de organización macroestructural, según representamos en (25): el primero, correspondiente a los títulos del TC; el segundo, a los capitulos. Para ambos se explicitan otros tantos temas macroproposicionales:

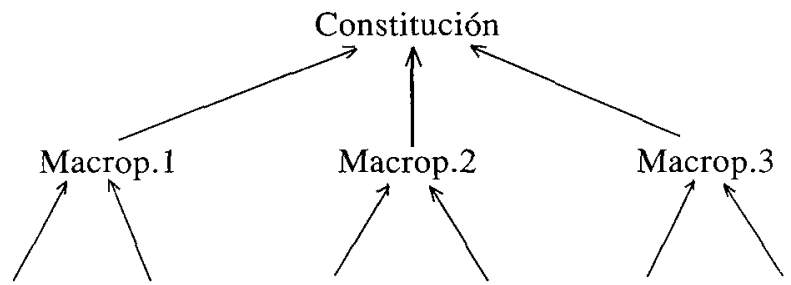

Macrop.1 Macrop.n Macrop.1 Macrop.n Macrop.1 Macrop. $\mathrm{n}$

${ }^{29}$ Diferenciamos entre Constitución como denominación común de este tipo de textos, y «constitución» o elemento específico de su superestructura. 
El grado de mayor complejidad en la organización interna del objeto de los TTCC concurre en Constituciones como las de México o El Salvador, triplemente estructuradas, según representamos en (26), y correspondiendo los tres niveles de estructuración a títulos, capítulos y secciones en ambos TTCC:

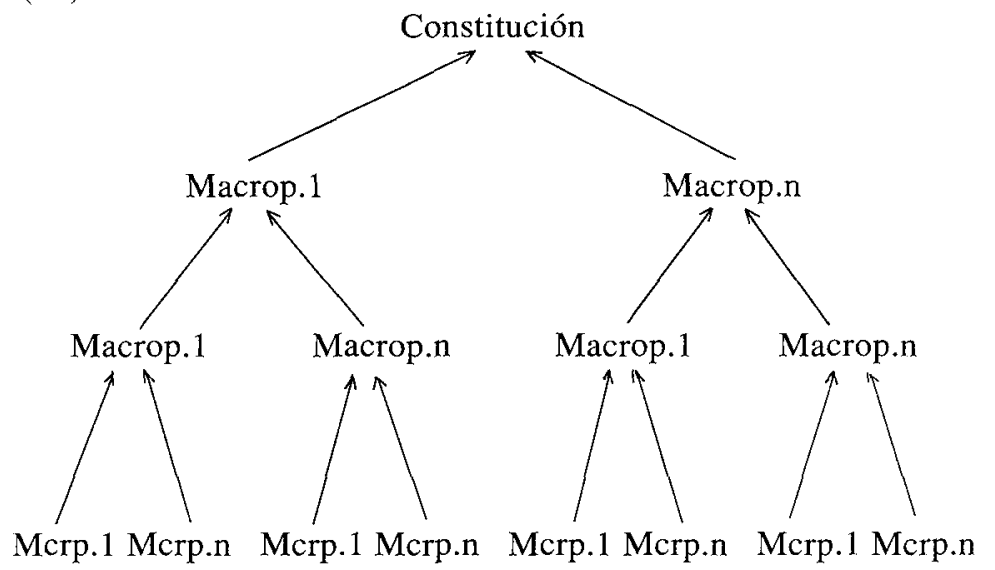

Establecíamos en (11) y (12) los tipos generales de mecanismos de síntesis y análisis, respectivamente, mediante los cuales puede explicarse la relación entre microestructuras y macroestructuras textuales. Es necesario puntualizar que tales mecanismos de recepción / producción textual tienen realmente una funcionalidad de mayor alcance que la de la simple conexión entre macroestructuras y microestructuras, debiendo, en realidad, ser considerados como operaciones que conectan cualesquiera niveles de estructuración diferentes dentro de la jerarquía de organización del texto.

$\mathrm{El}$ análisis de los TTCC iberoamericanos pone de manifiesto la operatividad de un reducido número de tales reglas o mecanismos en su caso, lo que constituye, pues, una nueva peculiaridad tipológica. En concreto, sólo dos, básicamente, de los cuatro procedimientos mencionados en (11) y (12) pueden ser encontrados en estos TTCC: los mecanismos de omisión y generalización, desde la perspectiva de la recepción textual, y sus contradictorios, desde la de la emisión, a la que atendemos fundamentalmente en este trabajo, los de añadido y particularización.

Exclusivamente desde la perspectiva de la producción textual-constitucional, el análisis o desarrollo de la macroestructura de los TTCC iberoamericanos resulta en gran medida de la operatividad de los mecanismos que, a título provisional, hemos denominado de añadido, en virtud de los cuales un determinado estadio o elemento macroestructural « $\mathrm{X}$ » es desarrollado en -estructuralmente, por tanto, domina a-estadios macroestructurales ulteriores 
$(« x+1 »)$, de forma que « $x »$ está siempre incluido explícitamente en « $x+1 »$ formando parte de su contenido macroproposicional, globalmente diferente del de «x», que no puede ser deducido lógicamente del de « $\mathrm{x}+1 »$. Tal es, por no citar más que un solo ejemplo, la relación de conexión que tiene lugar, en la Constitución de Puerto Rico, entre la macroproposición correspondiente a su ARTículo I (Del Estado Libre Asociado) y las macroproposiciones de las SECCIONES 1-4 que aquel engloba, en las que el Estado Libre Asociado funciona como tema macroproposicional objeto de las predicaciones desarrolladas en las cuatro SECCIONES.

Una importancia cuantitativa semejante a la de los mecanismos de añadido poseen los de particularización, sumamente frecuentes también en los TTCC. Con su concurso, un estadio o elemento macroproposicional «x», que funciona como superordenado conceptual de otros ulteriores « $\mathrm{x}+1$ », es analizado en estos últimos que, por tanto, literalmente no repiten -0 coinciden conningún elemento de «x». Es el caso, en la misma Constitución de Puerto Rico, de su ARTículo VI, cuyo contenido macroproposicional (Disposiciones generales) es el superordenado lógico del contenido de la macroestructura correspondiente a las SECCIONES $1-9$ que incluye.

Un caso particular de organización de la información semántica macroestructural, no mencionado en la tipología de Van Dijk ni en la propuesta por nosotros como la contradictoria lógica que correspondería al proceso de producción textual —vid. (11) y (12) - es el de los estadios macroproposicionales compuestos, relativamente frecuentes en los TTCC. Tal caso es, lógicamente, posible en la organización estructural de las unidades de cualquier nivel lingüístico, virtualmente sujetas a la operatividad de los mecanimos de recursividad. Este recurso es, como indicábamos, de frecuente uso en los TTCC. En la Constitución de Nicaragua, el Título vi presenta una macroproposición compuesta por coordinación (Economía Nacional. Reforma agraria y finanzas públicas) cada uno de cuyos constituyentes nucleares es, ulteriormente, desarrollado en las macroproposiciones correspondientes a los CAPítulos I-II, respectivamente, Economía Nacional, Reforma agraria y De las finanzas públicas. En la del Salvador, el capítulo i del título I presenta, a su vez, una compuesta equivalente a su título: Derechos individuales y su régimen de excepción, ulteriormente desarrollada en las macroproposiciones correspondientes a las SECCIONES I-II, respectivamente, Derechos individuales y Régimen de excepción. Algo semejante sucede en la Constitución de Filipinas, en su SECCIón II (Declaración de principios y de la política del Estado), o en la de Portugal, en la que tal recurso es especialmente utilizado, por ejemplo, en la PARTE III, Título I, ARTículo 111, 114, 117, etc.

La identidad de los mecanismos de organización y desarrollo de la macroestructura textual global de los TTCC, especialmente la ausencia notada de los mecanismos que hemos denominado de desarrollo y deconstrucción 
constituye una nota tipológicamente relevante para la caracterización de tales textos, cuya condición normativa-legal y cuya condición ilocutiva «constituyente» hacen perfectamente comprensible la no operatividad en su caso de tales mecanismos. Los TTCC son, en efecto, textos que «constituyen» una situación determinada, un espacio social de convivencia reglada creado precisamente por tales textos. Dicha funcionalidad ilocutiva parece estar, lógicamente, asociada a la no «naturalidad» o necesidad de los principios establecidos, cuya existencia y razón de ser misma no resultan de ninguna lógica exterior al TC, sino que son producto de la misma organización discursiva que los enuncia. Parece, pues, lógico que entre los mecanismos o reglas de organización textual de los TTCC no estén presentes aquellos que, como el desarrollo y la deconstrucción, suponen unas relaciones de implicación lógica entre los elementos por ellos vinculados.

La condición de unidad mínima dotada de autonomía comunicativa, propia de todo texto, les viene a éstos del requisito fundamental de una organización macroestructural adecuada, cuya naturaleza hemos intentado caracterizar someramente en las páginas precedentes.

Esta condición textual básica puede estar complementada por la existencia de otro nivel de organización estructural no poseido, necesariamente, por cualquier tipo de textos; por la posesión de lo que Van Dijk ha denominado la superestructura textual ${ }^{30}$.

El concepto metalinguístico de superestructura denota un determinado esquema de organización textual que gobierna la macroestructura global de ciertos textos. El conjunto de textos posibles puede, así, dividirse en los subconjuntos $/ \mathrm{T}+$ Superestructura/ vs. $/ \mathrm{T}$ - Superestructura/, siendo los segundos aquéllos en los que, como indicábamos, la organización textual se agota en el nivel de la macroestructura, y los primeros aquéllos en los que ésta resulta pertinentizada, utilizada como materia que la superestructura formaliza 0 informa en un modo preciso, narrativo, argumentativo..., etc.

La presencia de este nivel de estructuración textual, no requerido necesariamente para que un acto discursivo posea la condición de «texto», está en relación bien directa con el grado de socialización o relevancia colectiva institutucionalizada de un tipo textual, constituyendo una especie de fijación o codificación suplementaria añadida a la organización macroestructural.

La existencia de esquemas superestructurales en los textos, y, por consiguiente, la existencia misma de tipos textuales aparece así como un proceso similar al que, en un ámbito de problemas muy diferente, determinan la condición De lengua o dialecto de un sistema «dialectal»: el ensanchamiento de la finalidad a que un sistema lingüístico se destina (el acrecentamiento en el número de sus usuarios, la necesidad de su utilización como instrumento administrativo..., etc.) determina unas necesidades de fijación normativa que acaban por conferir

${ }^{30}$ Cfr. Teun A. Van Dijk: La ciencia del texto, cit., pp: 141-172. 
a dicho sistema la condición de lengua y no de mero dialecto ${ }^{31}$. En modo similar, la institucionali-zación de un determinado tipo de relación comunicativa acaba por fijar un cierto tipo de esquemas normativos a los que un acto discursivo debe acomodarse para ser reconocido colectivamente como formando parte de un «género» preciso. Este esquema de organización suplementaria es lo que se denomina la superestructura textual.

En todo caso, los TTCC presentan esta manera de estructuración particular; son textos dotados de una organización superestructural que se instituye en el nivel de mayor relevancia jerárquica del texto y, como tal, determina el modo concreto de estructuración de los niveles inferiores, tanto de la macroestructura como de la microestructura textual.

La organización superestructural de un texto puede ser descrita en forma de proposiciones que podemos denominar superproposiciones. Éstas pueden ser formalizadas como predicaciones atributivas del tipo general de (27), siendo «X» un atributo y «A» un actante-sujeto como/ser nudo de la narración/, en el caso de los textos de superestructura narrativa, /ser conclusión de la argumentación/ en el de los de superestructura argumentativa, o/ser título, capitulo, sección..., etc. de la constitución/ en el de los TTCC.

\section{(27)}

\section{Atribución de $\mathrm{X}$ a $\mathrm{A}$}

Como principio indisociable del concepto mismo de superestructura, las proposiciones de la superestructura textual están sujetas a la condición evidente de que su número sea mayor que 1 , siendo, pues, suficiente la presencia de 2 superproposiciones para la existencia de textos dotados de este nivel de organización.

Esta serie de predicaciones, como conjunto de $\langle\mathbf{n}>1 »$ número de elementos virtuales, posee una estructura sintáctica que puede también —en la línea de nuestras consideraciones para el mismo componente del nivel macroestructuralser descrita en términos de las categorías y clases de relaciones sintácticas posibles en su caso.

Como categorías, las relaciones que las dos superproposiciones básicas establecen para con el constituto superestructura textual -teniendo en cuenta su obligatoriedad - serán de nuclearidad/interdependencia: la existencia de la meta-unidad superestructura requiere el concurso de, al menos, estas dos superproposiciones, igualmente nucleares para con el todo de que forman parte $\mathrm{y}$, respecto del cual, constituyen, pues, un bloque interdependientemente solidario frente al resto de superproposiciones constituyentes virtuales que, por no imprescindibles para la constitución mínima o esencial de la unidad texto-

${ }^{3}$ Cfr. M. Alvar: «Hacia los conceptos de lengua, dialecto y hablas», N.R.F.H., XV, 1961, pp: 57 especialmente, $\mathrm{y}$ «Lengua, dialecto y cuestiones conexas», L.E.A., I-1, 1979, pp: 5-29. 
dotado de superestructura, establecerán para con él relaciones de marginalidad.

En este sentido, los TTCC se revelan como textos sin mayores particularidades tipológicas, más allá de su pertenencia a un tipo categorial en el que se integrarán todos aquellos dotados de 2 elementos superestructurales.

Las peculiaridades tipológicas máximamente distintivas de los TTCC provendrán, naturalmente, de la dimensión de lo que hemos denominado sus clases de relaciones sintácticas y, en especial de sus clases morfosemánticas, resultado de la concreta constitución de los TTCC a partir de los elementos preámbulo y constitución.

Hemos indicado cómo, desde un punto de vista categorial, los TTCC, en su dimensión superestructural, obedecen a un esquema de organización como (28), con dos elementos superproposicionales nucleares y sujetos a una relación de interdependencia mUtua pues su existencia es sìmultáneamente necesaria.

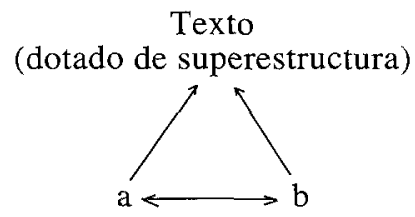

La condición de textos de los TTCC descansa sobre esta organización. Su condición de textos constitucionales, sin embargo, lo hace sobre la base de la identidad específica de cada uno de los constituyentes superproposicionales, cuya identidad morfosemántica determina la de los demás: la existencia en la superestructura de los TTCC de una superproposición con el contenido «constitución» será incompatible con la presencia simultánea de superproposiciones con el contenido conclusión (característica de los textos argumentativos), historia (propia de los textos narrativos)..., etc. Así pues, la organización estructural categorial que representábamos en (28) adquiere, desde la perspectiva de clase, la forma de (29), como resultado de la materialización de la condición de «texto» de los TTCC en la condición de «tipo o género textual específico».

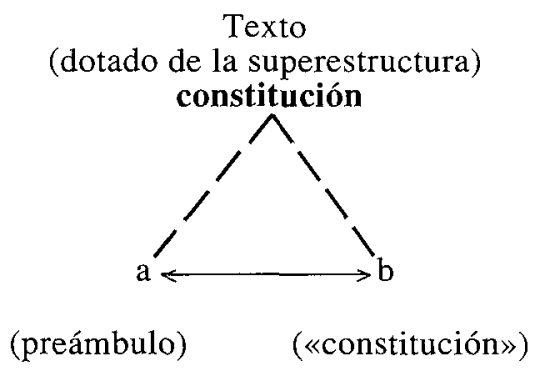


Siempre en el orden de las relaciones parte-parte, es posible encontrar un nuevo rasgo tipológico de los TTCC, en lo que se refiere al plano de su superestructura, atendiendo a la naturaleza de sus constituyentes y tomando en consideración, como lo hiciéramos al estudiar el plano macroestructural, la operatividad de los mecanismos de recursividad. Nada hay en el plano categorial de la superestructura textual que obligue a la opción por una de las dos posibilidades de articulación de los constituyentes superestructurales: simples / compuestos o complejos, respectivamente (30), (31) y (32), por no tomar en consideración más que las posibilidades elementales y no también las que resultarían de la combinatoria de los dos últimos esquemas:

(30)

unidad constituto................
unidades constituyentes.......

(31)

unidad constituto................

unidades constituyentes....Y $+\mathrm{Y}$

(32)

unidad constituto................

unidades constituyentes.... Y(Z)

A pesar de que, como indicábamos, nada hay en el plano de la superestructura textual, como nivel abstracto de organización, que determine la necesidad de opción por una de las alternativas de constitución frente a las restantes, la vastedad de aspectos que los TTCC han de cubrir parece difícilmente compatible con la ausencia de mecanismos de recursividad. De hecho, la clase «constitución» de la categoría de predicados superestructurales en los TTCC se conforma o compone sistemáticamente de un conjunto variable de elementos constituyentes, no muy homogéneamente denominados ni estructurados en el caso de los TTCC iberoamericanos ${ }^{32}$, pero que muestran en todo caso una constante tipológica de análisis de la generalidad predicativa constitucional en niveles sucesivos de

${ }^{32}$ Un estudio de detalle sobre estas y otras heterogeneidades de los textos legales se encontrará en el volumen Curso de técnica le gislativa del Grupo de Estudios de Técnica Legislativa GRETEL, Madrid, Centro de Estudios Constitucionales, 1989. Especialmente interesante desde el punto de vista que aquí nos ocupa resultan los capítulos «Teoría y técnica de la legislación. Metabibliografía y biliografía básicas», de Pablo Salvador Coderch, pp: 291-304, y el titulado «Borrador de directrices sobre la forma y estructura de las leyes», del GRETEL, pp: 305-323. 
menor generalidad, cada uno de los cuales presenta comúnmente una organización regida por mecanismos de composición, de manera que los constituyentes, «Y», de cada nivel jerárquico, «n», de la superestructura suelen presentarse, en términos glosemáticos, como constelaciones de elementos $(\mathrm{Y}+\mathrm{Y}+\mathrm{Y} \ldots)$, al mismo tiempo, de otra parte, que cada una de las unidades de un cierto nivel superestructural articula - a través de mecanismos de complejidad-a unidades de niveles distintos que se encuentran en relación de determinación para con aquéllas. La heterogeneidad en la denominación y en la estructuración jerárquica misma de los diferentes niveles superestructurales en el caso de los TTCC iberoamericanos puede, muy bien quedar reflejada en (33), un esquema que recoge las principales variaciones observables en estos textos.

País Organizac. superestruct. de constitución

\begin{tabular}{|c|c|c|c|c|}
\hline Salvador & Título & Capítulo & Sección & Artículo \\
\hline Filipin. & $\mathrm{e}$ & $\begin{array}{lll}\mathrm{c} & \mathrm{c} & \mathrm{i}\end{array}$ & ó & Artículo \\
\hline P. Rico & $\begin{array}{ll}\mathrm{A} & \mathrm{r}\end{array}$ & $\begin{array}{lll}\mathrm{t} & \mathrm{i} & \mathrm{c}\end{array}$ & $\begin{array}{ll}\mathrm{u} & 1\end{array}$ & Sección \\
\hline Chile & $\mathrm{C}$ & í & u $\quad$ l & Artículo \\
\hline México & Título & Capítulo & Sección & Artículo \\
\hline Nicaragua & Título & C a p í & $\begin{array}{llll}\mathrm{t} & \mathrm{u} & \mathrm{l} & \mathrm{o}\end{array}$ & Artículo \\
\hline Portugal & Parte & Título & Artigo & --- \\
\hline
\end{tabular}

